\title{
MRSBulletin Turning the page
}

\section{Behind \\ the themes and between the lines}

W ith this letter my two-decade run as MRS Bulletin editor comes to a close, and Gopal Rao moves into the editorship. He brings with him many years as MRS Web Science Editor and a rich background in materials science. I will take on a new role as the Materials Research Society's Principal Development Editor, working with the materials community to identify emerging fields in materials science, developing new print and electronic products, and bridging communication with other components of MRS to foster activities that complement and enhance the publications portfolio. Tim Palucka joins the MRS team as Science News Editor, coordinating news coverage across our various publication platforms. Together we form a science team to keep a finger on the pulse of the materials community and to usher content through MRS's expanding media outlets, now in partnership with Cambridge University Press (see Society News on p. 300).

These new positions reflect a natural progression as MRS tracks the accelerating role of materials research to address global needs in a resource-constrained world. Progress in regions throughout the world comes back to materials developments, whether shrinking computer components to bring a flatter world, scaling up energy technologies to raise the economic standards of billions of people, or designing new biomedical therapies to enhance the lives of an aging population. There is a lot of work to do.

Part of that progression has pushed MRS Bulletin beyond its usual size and format. Addressing the topic of energy alone, an initiative propelled by V.S. Arunachalam (CSTEP), has generated the Bulletin's April 2008 special and expanded issue, "Harnessing Materials for Energy," the www. materialsforenergy.org blog and website, collaborative forums around the world, and the ongoing Bulletin section EnERgy QuARTERLy. But this is just the start. With our expanded team, MRS Bulletin will be better equipped to explore a range of challenges ahead, with room to grow through companion publications and events.

Each development is built not by a single act, but by a collection of insights, of voices, and of long days in the lab and office. It is the relationships we have built day by day that help us rally as an interconnected community behind the larger challenges.
While those connections alone cannot hold back a tsunami, prevent every materials failure, or bring peaceful solutions to areas of political unrest, the science, words, and understanding we have built as a community brings comfort, hope, and - in time-solutions.

Whether looking for ways to safely manage nuclear waste, integrate sun and wind energy into the wires to our homes, or design nanoparticles to deliver drugs to disease sites, the diverse materials community continues to rally around common topical interests to solve problems. Each MRS Bulletin theme represents one of these communities, a group of colleagues in the field talking to one another, shaving away the fat, and synthesizing a body of knowledge that others can build upon.

It has been an honor and a privilege to have served as editor of MRS Bulletin and to have seen that network of voices expand and diversify. From the early days without e-mail or the Web (how did we know anything or anyone back then??) and with guest editors chosen with a simple nod to an eager researcher, we have evolved to a globally connected 24/7 operation, with a network of authors, guest editors, volume organizers, editorial board members, and other contributors spanning the globe and providing a robust system of checks and balances. It is this network of people led by Paul Drzaic as chair of the editorial board that I would like to thank for their insights and dedication and their ability to stitch together a greater understanding of our materials world.

I must personally thank the MRS Bulletin editorial staff for their dedication, talent, and support. They are the engine of MRS Bulletin's operation. This team, along with a range of staff members and external contributors, has brought professionalism and quality to the pages of the Bulletin and will ensure a smooth transition and strong support going forward.

I look with great anticipation to Gopal Rao as the new editor, to see MRS Bulletin grow and evolve.

Likewise, in my new role, I expect to strengthen and expand relationships with the materials community.

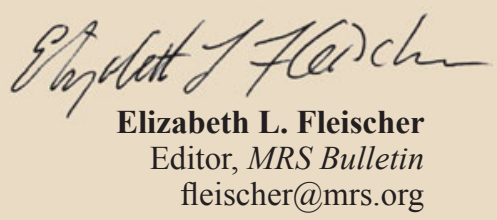

